\title{
Marcha de absorção de nutrientes e crescimento de mudas de caramboleira enxertada com a cultivar nota-10
}

\section{Growth and uptake of nutrients curves in star fruit plants budded with nota 10 cultivar}

\author{
Narimã Freitas ${ }^{1}$; Renato de Mello Prado²; Danilo Eduardo Rozane ${ }^{3 *}$; Mariana \\ Hortense Torres $^{1}$; Marina Burani Arouca ${ }^{1}$
}

\begin{abstract}
Resumo
O adequado estado nutricional das mudas de caramboleira permite o sucesso da implantação de um pomar. O objetivo deste trabalho foi determinar a marcha de absorção de nutrientes e o crescimento de mudas enxertadas de caramboleira 'Nota 10' produzida em solução nutritiva. O delineamento experimental utilizado foi o inteiramente casualizado, com seis tratamentos e quatro repetições. Os tratamentos foram constituídos pelos tempos de coleta $(25 ; 50 ; 75 ; 100 ; 125$ e 150 dias após o início da brotação das borbulhas). As plantas foram avaliadas quanto a: altura, diâmetro do enxerto e do porta-enxerto, área foliar e massa da matéria seca (folhas, caule e raízes). Nos diferentes órgãos das mudas, determinou-se o acúmulo de macronutrientes. O acúmulo de massa seca das mudas de caramboleira apresentou ajuste sigmoidal, enquanto o acúmulo de nutrientes apresentou incremento quadrático, exceto $\mathrm{Mg}, \mathrm{P}$ e $\mathrm{Cu}$, que foi sigmoidal, obedecendo à seguinte sequência: $\mathrm{N}>\mathrm{K}>\mathrm{Ca}>\mathrm{P}>\mathrm{S}>\mathrm{Mg}>\mathrm{Fe}>\mathrm{Mn}>\mathrm{Zn}>\mathrm{B}>\mathrm{Cu}$, sendo maior nas folhas para todos os nutrientes, à exceção do $\mathrm{P}, \mathrm{Zn}, \mathrm{Fe}$ e $\mathrm{Cu}$. O período de maior exigência de nutrientes foi entre $90-150$ dias após o transplantio.

Palavras-chave: Carambola, nutrição mineral, acúmulo de nutrientes, exigência nutricional, Averrhoa carambola L.
\end{abstract}

\begin{abstract}
The nutritional state of star fruit seedlings must be adequate for a successful field implementation. The objective of the present work was to study the growth and uptake of macro e micronutrients curves by star fruit plants budded with Nota 10 cultivar in nutrient solution conditions. The experimental design was randomized complete blocks, with four replications and six treatments, which were consisted by the times of collects during the 150 days of the experiment (each 25 days). In each collection, the plant growth was evaluated by the division of the plants in root, stem and leaves in order to obtain the height, diameter of the stem, leave area and the dry matter. The accumulation of dry matter followed sigmoidal adjustment, while the uptake of nutrients followed quadratic adjustment, except $\mathrm{Mg}, \mathrm{P}$, and $\mathrm{Cu}$ that followed sigmoidal adjustment. The accumulation of nutrients by star fruit seedlings 'nota 10 ' followed the sequence: $\mathrm{N}<\mathrm{K}<\mathrm{Ca}<\mathrm{P}<\mathrm{Mg}<\mathrm{Fe}<\mathrm{Mn}<\mathrm{Zn}<\mathrm{B}<\mathrm{Cu}$, where the absorption of nutrients was bigger in leaves than the stem and roots, in exception of the $\mathrm{P}, \mathrm{Zn}, \mathrm{Fe}$ and $\mathrm{Cu}$. The period of greatest demand for nutrients was between 90 and 150 days after transplanting.
\end{abstract}

Key words: Star fruit, mineral nutrition, nutrient accumulation, nutritional exigency, Averrhoa carambola L.

1 Engenheiros Agrônomos. E-mail: narimaf@yahoo.com.br, mari hortense@yahoo.com.br; marinarouc@yahoo.com.br

2 Prof. Adjunto, Universidade Estadual Paulista “Júlio de Mesquita Filho", UNESP, Faculdade de Ciências Agrárias e Veterinárias de Jaboticabal, Departamento de Solos e Adubos, Via Acesso Prof. Paulo Donato Castellane, s/n, Jaboticabal, SP, CEP 14884900. E-mail: rmprado@fcav.unesp.br

3 Prof. Assistente Doutor, Universidade Estadual Paulista “Julio de Mesquita Filho", UNESP, Rua: Nelson Brihi Badur, n 430, Vila Tupy, CEP 11900-000. Registro, SP. E-mail: danilorozane@registro.unesp.br

* Autor para correspondência 


\section{Introdução}

A carambola ocupa lugar de destaque dentre as frutas tropicais devido às suas peculiares de cor, sabor, aroma, propriedades nutricionais, como fonte de vitamina $C, A, K$ e vários aminoácidos, além de sua beleza exótica e única na natureza, o que a torna muito atrativa ao consumidor.

O Brasil está dentre os principais produtores mundiais desta frutífera, sendo o Estado de São Paulo responsável por $68 \%$ da produção nacional (BASTOS, 2004), como a maior parte desta produção é proveniente de pequenos pomares, o que atende a um dos aspectos mais importantes da fruticultura, o social, permitindo a fixação do homem no campo.

A produção de mudas de caramboleira com adequado estado nutricional é um dos fatores primordiais que determina o sucesso na implantação do pomar, podendo influenciar no início da produção, refletindo no retorno econômico do capital investido pelo fruticultor.

Contudo, para a adequada nutrição das caramboleiras, além da quantidade acumulada e da relação entre nutrientes, é preciso conhecer a dinâmica de acúmulo dos nutrientes ao longo do tempo de cultivo, pois o desbalanço nutricional acarreta prejuízos às mudas, alterando sua taxa de crescimento.

A produção de mudas de caramboleira carece de trabalhos na área de nutrição mineral, em especial referentes à marcha de absorção. $\mathrm{O}$ que é motivo de preocupação, devido a utilização empírica da adubação, praticada pelos produtores de mudas, os quais empregam pouco conhecimento da exigência nutricional da frutífera ou da época adequada de fornecimento dos nutrientes, para produção das mudas, atribuindo consequências maiores ao sistema de produção, ao meio ambiente e ao produtor no estabelecimento da lavoura.

Trabalhando com mudas desta frutífera Bastos et al. (2007) avaliaram diferentes substratos; Rozane et al. (2007) diferentes soluções nutritivas para o cultivo hidropônico. Estando uma enorme lacuna a ser preenchida na fase de produção de mudas, podendo-se deduzir que um acompanhamento do crescimento e da marcha de absorção de nutrientes nas mudas de caramboleira pode traduzir-se em benefícios para os viveiristas e para os produtores.

O objetivo deste trabalho foi determinar a marcha de absorção de nutrientes e o crescimento de mudas enxertadas de caramboleira cultivar Nota 10, produzida em solução nutritiva.

\section{Material e Métodos}

O experimento foi realizado com mudas de caramboleiras (Averrhoa carambola L.) 'Nota 10' em casa de vegetação, na FCAV/Unesp Câmpus de Jaboticabal - SP, com coordenadas $21^{\circ} 15^{\prime} 22^{\prime \prime}$ sul, $48^{\circ} 18^{\prime} 58^{\prime}$ " oeste e altitude de $615 \mathrm{~m}$,

O delineamento experimental utilizado foi o inteiramente casualizado, com seis tratamentos constituindo pelos tempos de coleta $(25 ; 50 ; 75$; 100; 125 e 150 dias após o início da brotação das borbulhas) e quatro repetições. Sendo cada repetição a média de duas plantas, totalizando 8 plantas por coleta, as quais estavam acondicionadas em vasos de polipropileno, com $8 \mathrm{~L}$ de capacidade e formato trapezoidal. Durante o período experimental foi realizado rodízios dos vasos, para que todas as plantas recebessem as mesmas condições.

Os hipobiotos utilizados no experimento foram provenientes de propagação sexuada (sementes), como indicado por Donadio et al. (2001). Para isto, foram selecionados frutos maduros, em um pomar de caramboleiras adultas 'Malásia', na Estação Experimental de Citricultura de Bebedouro - SP, dos quais se extraíram as sementes, que foram cultivadas individualmente em tubetes plásticos de $53 \mathrm{~cm}^{3}$ contendo casca de pínus e vermiculita até 150 dias após sua germinação. Após este período, as raízes das plantas foram submetidas à lavagem, para a retirada de todo o substrato aderido ao sistema 
radicular, a fim de transplantá-las para o cultivo hidropônico, em solução nutritiva de Furlani et al. (1999), cuja composição química de macronutrientes, em mg. $L^{-1}$, é: $\mathrm{N}=202,0 ; \mathrm{P}=31,5 ; \mathrm{K}=193,4 ; \mathrm{Ca}$ $=142,5 ; \mathrm{Mg}=39,4$ e $\mathrm{S}=52,3$, e micronutrientes, em $\mu$ g. $\mathrm{L}^{-1}: \mathrm{B}=262 ; \mathrm{Cu}=38 ; \mathrm{Fe}=1800 ; \mathrm{Mn}=369$; $\mathrm{Mo}=65$ e $\mathrm{Zn}=114$, indicada como adequada para o cultivo de mudas de caramboleira, segundo Rozane et al. (2007).

Houve adaptação dos porta-enxertos durante os primeiros 15 dias após o transplante, sendo os mesmos mantidos em solução nutritiva completa, diluída a 1/4 da concentração usual e, após esse período até o final do experimento, a solução foi completa, sem diluição.

Após a adaptação, as mudas encontravam-se aptas a serem enxertadas, a qual foi realizada com a cultivar Nota 10. Esse procedimento foi realizado pelo método da borbulhia, com as mesmas técnicas e padrões utilizados para a produção de mudas nos viveiros comerciais, como preconizado por Donadio et al. (2001). Após 50 dias da realização da enxertia iniciou-se a brotação das borbulhas, considerando-se o início do período experimental, o qual decorreu até a formação da muda, apta a ser comercializada aos $150^{\circ}$ dia. Salienta-se que a primeira coleta das plantas foi realizada após completar 65 dias do transplantio e, consequentemente, as plantas estiveram em contato com a solução nutritiva completa durante 50 dias.

Para o manejo da solução nutritiva no experimento ao longo do período de estudo o $\mathrm{pH}$ da solução nutritiva foi monitorado diariamente, com o uso de um medidor portátil (Peagâmetro Gehaka ${ }^{\circledR} 1400$ ), e ajustado a 5,5 \pm 0,5, usando-se solução $\mathrm{NaOH}$ ou $\mathrm{HCl}$ 0,1 M L-1. A reposição da água evapotranspirada foi realizada com água destilada. A solução nutritiva dos vasos foi oxigenada constantemente, pelo uso de um borbulhador acoplado a um compressor de ar, e renovada a cada 25 dias, na ocasião da coleta das plantas.

A cada coleta foram avaliados: a altura, do colo da planta até a extremidade da última folha expandida; o diâmetro do porta-enxerto, a $8 \mathrm{~cm}$ do colo da planta e o diâmetro do enxerto, a $8 \mathrm{~cm}$ da enxertia, com auxílio de um paquímetro digital; a área foliar, determinada com o auxílio de um aparelho integrador de áreas portátil, LI-COR ${ }^{\circledR}$ modelo LI-3100. Em seguida, as plantas foram divididas em raízes, caule e folhas. Depois, todo o material vegetal foi lavado em água destilada e seco em estufa com circulação forçada de ar, à temperatura de 65 a $70^{\circ} \mathrm{C}$, até atingir massa constante. Foi quantificada a massa da massa seca das diferentes partes da planta e, em seguida determinouse os teores de nutrientes no tecido vegetal, seguindo a metodologia descrita por Bataglia et al. (1983). A partir do teor de nutrientes no tecido vegetal e de massa seca, calculou-se o acúmulo dos nutrientes nos diferentes órgãos das mudas de caramboleira.

Com base nos resultados, foram realizadas análises de variância (teste F) para as diversas características estudadas e a regressão para tempo de cultivo (SAS INSTITUTE, 1996). Em todas as variáveis, utilizou-se o modelo de regressão que resultou em significância pelo teste $\mathrm{F}$, e com maior coeficiente de determinação. Sendo o modelo sigmoidal, proposto por Hoffmam (1977) e representado pela equação:

$$
Y=\frac{a}{1+e^{-k\left(x-x^{c}\right)}}
$$

onde, a: é o máximo valor observado; $e$ : é o inverso do logaritmo neperiano; $k$ : é a taxa média de acúmulo; $x$ : dias após o transplantio; e $x^{c}$ : é o máximo acumulado durante os $50 \%$ de desenvolvimento das mudas.

\section{Resultados e Discussão}

Efeitos do tempo de cultivo nas variáveis de crescimento

Houve efeito significativo do tempo de cultivo sobre todas as variáveis de crescimento apresentados na (Tabela 1). 
Tabela 1. Valor do teste $\mathrm{F}(\mathrm{F})$ e coeficiente de variação $(\mathrm{CV})$ do fator tempo de cultivo sobre as variáveis de crescimento das mudas de caramboleira 'Nota 10' cultivada em solução nutritiva.

\begin{tabular}{|c|c|c|c|c|c|c|c|c|}
\hline \multirow[t]{3}{*}{ Variáveis } & \multirow[t]{2}{*}{ Altura } & \multicolumn{2}{|c|}{ Diâmetro } & \multirow[t]{2}{*}{ Área Foliar } & \multicolumn{4}{|c|}{ Massa seca } \\
\hline & & Porta-enxerto & Enxerto & & Folhas & Caule & Raízes & Planta \\
\hline & $-\mathbf{c m}-$ & \multicolumn{2}{|c|}{-------- mm -------- } & $--\mathbf{d m}^{2}--$ & \multicolumn{4}{|c|}{------------- g por planta ------------- } \\
\hline $\mathrm{F}$ & $89,99 * *$ & $20,51 * *$ & $55,00 * *$ & $267,61 * *$ & $367,69 * *$ & $173,75 * *$ & $29,40 * *$ & $393,69 * *$ \\
\hline $\mathrm{CV}(\%)$ & 11,3 & 10,6 & 6,8 & 13,3 & 11,5 & 11,6 & 13,2 & 7,7 \\
\hline
\end{tabular}

** : significativo pelo teste $\mathrm{F}(\mathrm{p}<0,01)$.

Observa-se que a altura e a massa da matéria seca do caule apresentaram comportamento quadrático, na área foliar, na massa seca das folhas e da planta inteira, o comportamento foi sigmoidal, e a massa seca das raízes, juntamente com os diâmetros do porta-enxerto e do enxerto apresentaram comportamento linear ao longo do tempo de cultivo (Tabela 2). Resultados semelhantes foram obtidos em mudas de goiabeira cultivadas em solução nutritiva, com incremento sigmoidal na altura e diâmetro do caule, porém, linear para a área foliar da 'Pedro Sato' (AUGUSTINHO et al., 2008), linear para a altura, área foliar e diâmetro do caule ao longo do cultivo de goiabeiras 'Paluma' e 'Século XXI' (FRANCO et al., 2007).

Tabela 2. Equações, Valor do teste F (F) e coeficiente de determinação (R2) encontradas nos estudos de regressão sobre o efeito do tempo de cultivo (dias) no crescimento das mudas de caramboleira 'Nota 10' cultivada em solução nutritiva.

\begin{tabular}{llll}
\hline Variáveis & Equação & Teste $\mathbf{F}$ & $\mathbf{R}^{2}$ \\
\hline Altura $(\mathrm{cm})$ & $\hat{\mathrm{y}}=0,0033 \mathrm{x}^{2}+0,1744 \mathrm{x}+21,432$ & $10,79^{* *}$ & 0,96 \\
Diâmetro porta-enxerto $(\mathrm{mm})$ & $\hat{\mathrm{y}}=0,025 \mathrm{x}+5,4793$ & $99,32^{* *}$ & 0,97 \\
Diâmetro enxerto $(\mathrm{mm})$ & $\hat{\mathrm{y}}=0,0385 \mathrm{x}+1,24$ & $268,38^{* *}$ & 0,98 \\
${\text { Área foliar }\left(\mathrm{dm}^{2}\right)}^{\text {Massa seca das folhas }}{ }^{1}$ & $\hat{\mathrm{y}}=16003,64105 /\left(1+\mathrm{e}^{-0,0267(\mathrm{x}-365,94928)}\right)$ & $184,95^{* *}$ & 0,99 \\
Massa seca do caule $^{1}$ & $\hat{\mathrm{y}}=3149,81 /\left(1+\mathrm{e}^{-0,0272(\mathrm{x}-337,445)}\right)$ & $293,32^{* *}$ & 0,99 \\
Massa seca das raízes $^{1}$ & $\hat{\mathrm{y}}=0,001 \mathrm{x}^{2}-0,0696 \mathrm{x}+3,646$ & $95,18^{* *}$ & 0,97 \\
Massa seca da planta inteira $^{1}$ & $\hat{\mathrm{y}}=0,0524 \mathrm{x}+2,212$ & $139,89^{* *}$ & 0,95 \\
\hline
\end{tabular}

** : significativo pelo teste $\mathrm{F}(\mathrm{p}<0,01) .{ }^{1}$ expresso em (g por planta).

Esse incremento da área foliar das mudas do presente trabalho pode ser explicado pelo acúmulo sigmoidal da massa seca das folhas (Tabela 2). Observa-se que o incremento significativo dos parâmetros avaliados ocorreram a partir da primeira avaliação, evidenciando, a adequada distribuição das coletas e o crescimento vigoroso das plantas.

Na partição da planta, as variáveis de massa seca estudadas apresentaram ajuste sigmóide no 
acúmulo de massa seca das folhas, quadrático no caule, linear nas raízes e sigmóide na planta inteira (Tabela 2). Cabe então salientar que a curva de crescimento da muda (planta inteira) da caramboleira segue a curva sigmóide, padrão este amplamente relatado na literatura, e em inúmeras culturas, cultivares e locais e sistemas de produção, a exemplos do mamão (CUNHA, 1979), do tomateiro (FAYAD et al., 2002), da melancia (GRANGEIRO; CECÍLIO FILHO, 2004), e da goiabeira (AUGUSTINHO et al., 2008). Já Franco et al. (2007) verificaram ajuste quadrático para a massa seca dos diferentes órgãos de mudas de goiabeira 'Paluma' e Século XXI'. Esse acúmulo quadrático de massa seca também foi relatado em outras culturas na fase de produção de mudas, como em eucalipto (SILVEIRA et al., 2003) e em gravioleira (BARBOSA; SOARES; CRISÓTOMO, 2003).

Observa-se, ainda, que as mudas de caramboleira atingiram metade do crescimento em altura, área foliar, diâmetro do porta-enxerto e do enxerto nos períodos de 87; 125; 87 e 99 dias (Tabela 2), respectivamente, sendo observado um crescimento maior depois da metade do tempo decorrente do experimento, indicando um lento crescimento inicial. Barbosa, Soares e Crisótomo (2003) também verificaram, em mudas de gravioleira, que o crescimento inicial das plantas foi caracterizado por um pequeno incremento, até os 105 dias após a repicagem, em altura e diâmetro do caule. Já em mudas de goiabeira, metade do crescimento em altura e a área foliar, no estudo de Franco et al. (2007), foi de 62 a 79 e dos 65 a 72 dias, para a 'Paluma'e 'Século XXI', respectivamente, em um cultivo de 120 dias. Augustinho et al. (2008), para a goiabeira 'Pedro Sato', obtiveram metade do crescimento do diâmetro do caule, altura e área foliar, nos períodos de 59; 70 e 60 dias, respectivamente, em média, na metade do tempo decorrente do experimento.

Esse crescimento vigoroso das mudas de caramboleira, durante o período de condução, concorda com Barbosa, Soares e Crisótomo (2003), que observaram o mesmo comportamento no acúmulo de massa seca em mudas de gravioleira cultivadas em vaso. Cunha (1979) também evidenciou comportamento semelhante para o acúmulo de massa seca da parte aérea da cultura do mamoeiro ao longo do cultivo; entretanto, o trabalho foi desenvolvido em condições de campo.

As plantas de caramboleira apresentaram metade da sua massa seca total das folhas, caule, raízes e planta inteira, respectivamente, aos 126; 82; 91 e 118 dias (Tabela 2), mostrando desenvolvimento inicial lento, conforme verificado anteriormente para as variáveis de crescimento. Barbosa, Soares e Crisótomo (2003) obtiveram resposta semelhante em mudas de gravioleira que acumularam metade da massa seca total aos 141 dias, e o restante até 195 dias.

Grangeiro e Cecílio Filho (2004), em experimento realizado com melancia, observaram que o crescimento da planta, expresso pelo acúmulo de massa seca ao longo do ciclo, foi lento até 30 dias após o transplantio, intensificando-se a partir deste.

Para caramboleira a produção de massa seca, aos 150 dias de cultivo, foi de 45,65 g por planta; e o acúmulo de biomassa ocorreu na seguinte sequência: folhas $(42 \%)>$ caule $(35 \%)>$ raízes (23\%) (Tabela 2). Esse maior acúmulo da biomassa no órgão folha também foi encontrado em mudas de goiabeiras (FRANCO et al., 2007, AUGUSTINHO et al., 2008), em gravioleira (BARBOSA; SOARES; CRISÓTOMO, 2003) e em eucalipto (SILVEIRA et al., 2003). Esse fato ocorreu, provavelmente, porque o dreno de assimilado preferencial foram as folhas, resultando, assim, em maior acúmulo de massa seca, pois as raízes e o caule não apresentaram alta capacidade mobilizadora de assimilados. Portanto, nessa fase de desenvolvimento inicial da 
caramboleira, a mesma investe mais na produção de biomassa das folhas, possivelmente para incrementar a área foliar e a taxa fotossintética com reflexo na biomassa da planta inteira. Haynes (1980) relata a alta correlação do índice de área foliar e a produção de massa seca.

\section{Efeito do tempo de cultivo no acúmulo de nutrientes}

Houve efeito significativo do tempo de cultivo sobre o acúmulo em todos os nutrientes estudados, nos diferentes órgãos das mudas de caramboleira ao longo do cultivo (Tabela 3). A exceção do $\mathrm{Cu}$ nas folhas e no caule, que resultou na não-significância dos modelos de regressão estudados, provavelmente pela aplicação de fungicidas cúpricos ao longo do tempo de cultivo, para o controle de doenças, bem como o pincelamento com pasta cuprica, na incisão do epibioto logo acima da enxertia.

De modo geral, os maiores acúmulos dos diversos nutrientes e órgãos estudados ocorreram ao final do período experimental (150 dias), à exceção do $\mathrm{Ca}$ nas raízes, que apresentou o máximo acúmulo entre 50 e 75 dias; B nas raízes; $\mathrm{Mn}$ no caule e nas raízes, e $\mathrm{Cu}$ nas folhas, caule, raízes e também na planta inteira, sendo que o máximo ocorreu entre 100 e 125 dias (Tabela 4).

Augustinho et al. (2008) em mudas de goiabeira 'Pedro Sato', observaram ajuste linear somente no acúmulo de $\mathrm{Mg}$ nas folhas e caule, e de Mn no caule, sendo-nos demais nutrientes observados ajustes sigmóides para o acúmulo nas folhas, caule e raízes. Franco et al. (2007), trabalhando com a 'Paluma' e 'Século XXI', observaram incrementos lineares e quadráticos para todos os nutrientes nas folhas, caule e raízes, entretanto, tais autores não avaliaram o comportamento sigmoidal nas variáveis estudadas.
Ao $150^{\circ}$ dia, para mudas de caramboleira foram encontrados para o acúmulo de macronutrientes nas folhas (em mg por planta): $\mathrm{N}=606 ; \mathrm{P}=41$; $\mathrm{K}=507 ; \mathrm{Ca}=156 ; \mathrm{Mg}=88$ e $\mathrm{S}=84$, no caule: $\mathrm{N}=222 ; \mathrm{P}=64 ; \mathrm{K}=261 ; \mathrm{Ca}=134 ; \mathrm{Mg}=57$ e $\mathrm{S}=25$, e nas raízes: $\mathrm{N}=230 ; \mathrm{P}=54 ; \mathrm{K}=103 ; \mathrm{Ca}=57 ; \mathrm{Mg}=28$ e $\mathrm{S}=38$. Tendo, dessa forma, o acúmulo de $\mathrm{N}, \mathrm{P}$, $\mathrm{K}, \mathrm{Ca}, \mathrm{Mg}$ e S, na planta inteira, de: 1.058, 159, 871, 347, 123 e 147, respectivamente (Tabela 4).

Chu, Möller e Carvalho (2001), estudando a quantidade de nutrientes absorvida pelas mudas de gravioleira, observaram, quantidades inferiores nos acúmulos de nutrientes, o que pode ser evidenciado sobre tudo pela variação genética, contudo observaram que a ordem decrescente de acúmulo foi $\mathrm{N}, \mathrm{K}, \mathrm{Ca}, \mathrm{Mg}, \mathrm{P}, \mathrm{Fe}, \mathrm{Zn}, \mathrm{Mn}$ e $\mathrm{Cu}$. Já Barbosa, Soares e Crisótomo (2003) avaliando também gravioleiras observaram que a mesma ordem de acúmulo de macronutrientes, a exceção da inversão dos nutrientes $\mathrm{N}$ e K.

Em mudas de goiabeira, após 120 dias de cultivo hidropônico, Augustinho et al. (2008) encontraram os acúmulos na planta inteira (em mg por planta): $\mathrm{N}=340 ; \mathrm{P}=44 ; \mathrm{K}=380 ; \mathrm{Ca}=173$; $\mathrm{Mg}=33$ e $\mathrm{S}=40$, na 'Pedro Sato', e Franco et al. (2007): $\mathrm{N}=552$ e $585 ; \mathrm{P}=64$ e $66 ; \mathrm{K}=726$ e 696; $\mathrm{Ca}=293$ e 302; $\mathrm{Mg}=39$ e 41; $\mathrm{S}=73$ e 66, respectivamente, para 'Paluma' e 'Século XXI'. Sendo que este último apresenta valores próximos ao da presente pesquisa.

Para o presente trabalho, na ultima avaliação, aos 150 dias foram encontrados os valores para o acúmulo de micronutrientes nas folhas, em $\mu \mathrm{g}$ por planta: $\mathrm{B}=1162 ; \mathrm{Cu}=19 ; \mathrm{Fe}=1873 ; \mathrm{Mn}=4364$; $\mathrm{Zn}=830$; no caule: $\mathrm{B}=235 ; \mathrm{Cu}=16 ; \mathrm{Fe}=983$; $\mathrm{Mn}=663 ; \mathrm{Zn}=875$, e nas raízes: $\mathrm{B}=356 ; \mathrm{Cu}=580$; $\mathrm{Fe}=25215 ; \mathrm{Mn}=823 ; \mathrm{Zn}=566$. E o acúmulo na planta inteira foi de: $1753 ; 616 ; 28071 ; 5850 \mathrm{e}$ $2271 \mu$ g por planta, respectivamente, para $\mathrm{B}, \mathrm{Cu}$, Fe, Mn e Zn (Tabela 4). 


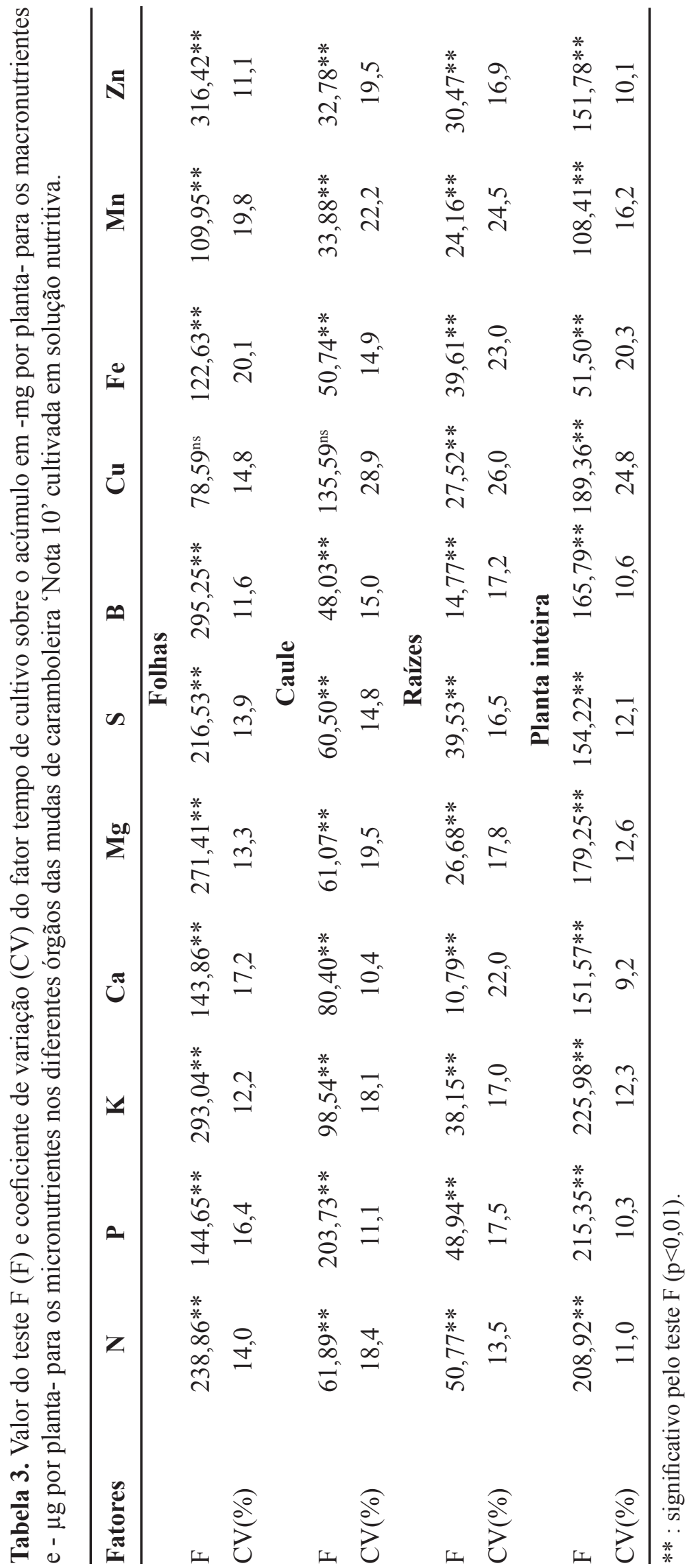




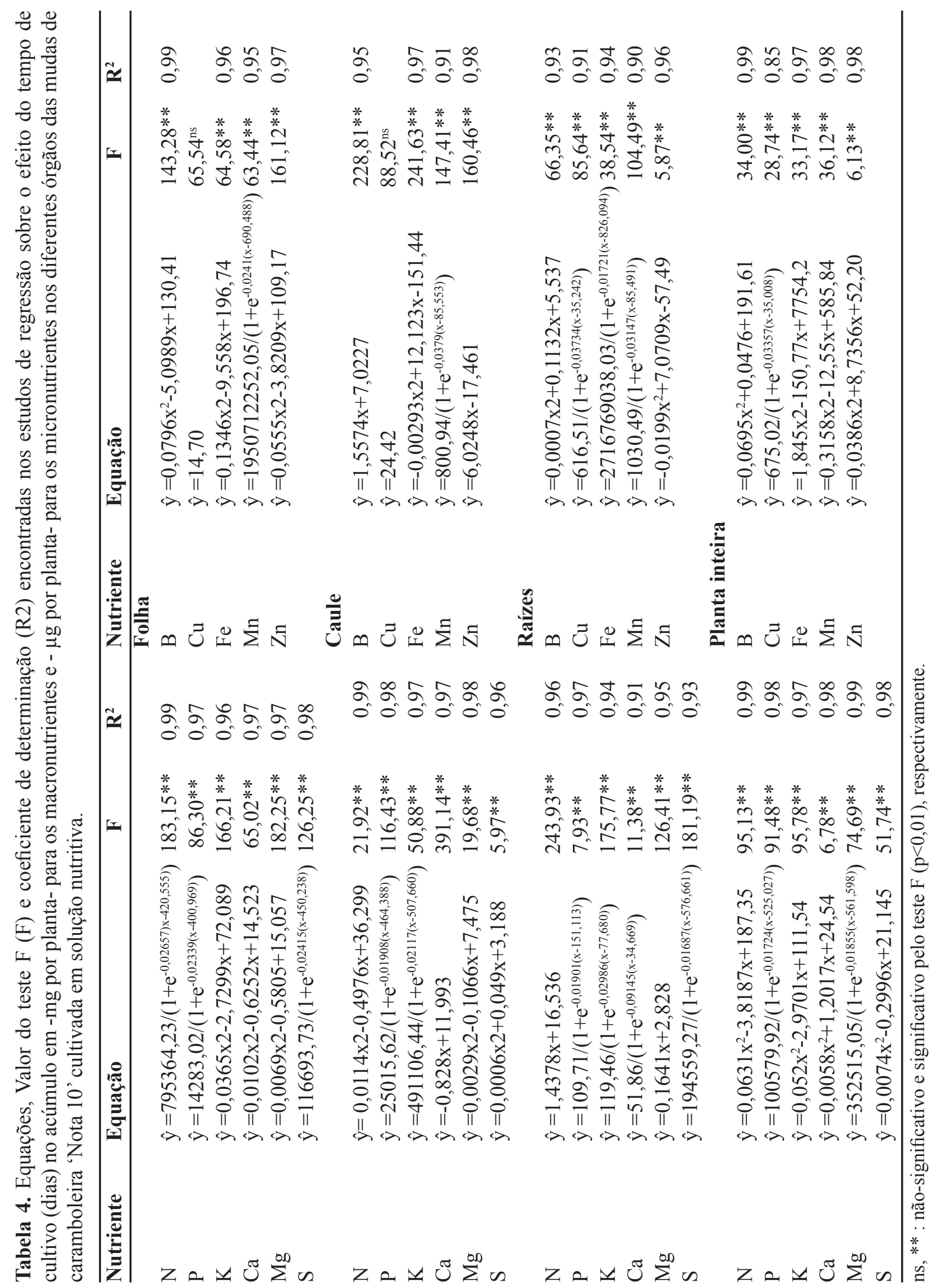


Para mudas de goiabeira em cultivo hidropônico, aos 120 dias, Augustinho et al. (2008) encontraram os seguintes valores para o acúmulo de micronutrientes nas folhas, em $\mu \mathrm{g}$ por planta: $\mathrm{B}=454 ; \mathrm{Cu}=20 ; \mathrm{Fe}=890 ; \mathrm{Mn}=1075$ e $\mathrm{Zn}=204 ;$ no caule: $\mathrm{B}=69 ; \mathrm{Cu}=13 ; \mathrm{Fe}=210 ; \mathrm{Mn}=3 \mathrm{IDEM}$ !!!!81 e $\mathrm{Zn}=135$, e nas raízes: $\mathrm{B}=221 ; \mathrm{Cu}=86 ; \mathrm{Fe}=4.014$; $\mathrm{Mn}=695$ e $\mathrm{Zn}=228$. Sob as mesmas condições, Franco et al. (2008) observaram os seguintes valores médios para o acúmulo de micronutrientes nas folhas, em $\mu$ g por planta: $\mathrm{B}=450 ; \mathrm{Cu}=69$; $\mathrm{Fe}=1.830 ; \mathrm{Mn}=1.905$ e $\mathrm{Zn}=424$; no caule: $\mathrm{B}=131$; $\mathrm{Cu}=41 ; \mathrm{Fe}=435 ; \mathrm{Mn}=525$ e $\mathrm{Zn}=186$, e nas raízes: $\mathrm{B}=127 ; \mathrm{Cu}=36 ; \mathrm{Fe}=4.554 ; \mathrm{Mn}=950$ e $\mathrm{Zn}=269$. Observa-se que dentre as variações o acúmulo de Mn e B sempre mostrou-se superior nas folhas, entretanto para caramboleira este acúmulo é mais de duas vezes superior ao acúmulo das mudas de goiaba. Já o Zn teve o maior acúmulo no caule e o $\mathrm{Fe}$ e $\mathrm{Cu}$ nas raízes das mudas de caramboleira 'Nota 10'. Resultados semelhantes foram relatados por Augustinho et al. (2008) e Franco et al. (2008), em mudas de goiabeira. Esses fatores dependem do material genético e do tempo de cultivo.

A soma de nutrientes acumulados pelas mudas de caramboleira na planta inteira, aos 150 dias foi de $2.743 \mathrm{mg}$, e considerando a massa seca da planta inteira (45.650 mg) (Tabela 2); portanto, os nutrientes acumulados na planta representaram $6,0 \%$ da massa seca. Este valor está próximo ao relatado por Haag et al. (1981) para culturas em geral $(5,0 \%)$ e por Augustinho et al. (2008) em mudas de goiabeira 'Pedro Sato' (5,3\%). Entretanto, muito inferior ao obtido por Silva Júnior et al. (2006) para a cultura do meloeiro (17\%).

Com base nos resultados, nota-se que o acúmulo de nutrientes pelas mudas de caramboleira 'Nota 10' obedeceu à sequência: $\mathrm{N}>\mathrm{K}>\mathrm{Ca}>\mathrm{P}>\mathrm{S}>\mathrm{Mg}>\mathrm{Fe}>\mathrm{Mn}>\mathrm{Zn}>\mathrm{B}>\mathrm{Cu}$. Corroborando com Chu, Möller e Carvalho (2001) e Rozane et al. (2007) que verificaram dentre várias culturas e condições de cultivo que o nitrogênio e o potássio são os nutrientes mais requeridos na fase inicial de desenvolvimento da planta. É conhecida a atuação do nitrogênio na divisão celular e na produção de clorofila, bem como do potássio em processos osmóticos, na síntese de proteínas e na manutenção de sua estabilidade, na permeabilidade das membranas e no controle do pH (MARSCHNER, 1995). Essa alta exigência dos nutrientes da planta, possivelmente, deve-se à intensa atividade metabólica nesta fase inicial de desenvolvimento.

Essa ordem difere dos valores encontrados no mesmo sistema de cultivo de mudas de goiabeira 'Pedro Sato' (AUGUSTINHO et al., 2008) e 'Paluma', e 'Século XXI' (FRANCO et al., 2007; FRANCO et al., 2008), que foi: $\mathrm{K}>\mathrm{N}>\mathrm{Ca}>\mathrm{S}>\mathrm{P}>\mathrm{Mg}>\mathrm{Fe}>\mathrm{Mn}>\mathrm{B}>\mathrm{Zn}>\mathrm{Cu}$. Segundo Grangeiro e Cecílio Filho (2004), o potássio foi também o nutriente mais absorvido pelo híbrido de melancia Tide. O que evidenciar a maior necessidade deste nutriente por estas culturas para desempenhar seu papel metabólico.

Comumente às mudas de caramboleira, Grangeiro e Cecílio Filho (2004), trabalhando com melancia, ressaltam que dentre os macronutrientes absorvidos em menores quantidades estão o $\mathrm{Mg}$, P e S. O magnésio, semelhantemente ao ocorrido com o cálcio, apresentou maior acúmulo nas folhas; muito provavelmente, por fazer parte da molécula de clorofila. De acordo com Marschner (1995), dependendo do teor de Mg na planta, pode ocorrer que grande parte do magnésio esteja ligada à molécula de clorofila, restando uma pequena quantidade ligada a pectatos na parede celular ou depositados como sal insolúvel no vacúolo.

Corroborando com Lopes et al. (1997), que estudaram em solução nutritiva a marcha de absorção de macronutrientes, em mudas de maracujazeirodoce. $\mathrm{O}$ acúmulo médio de macronutrientes pelas mudas de caramboleira também esteve concentrado nas folhas com aproximadamente $54 \%$, e o restante no caule (28\%) e nas raízes (18\%), somente o P teve maior acúmulo no caule. Em mudas de goiabeira, 
foram encontrados os seguintes acúmulos médios nas folhas com $65 \%$, no caule $17 \%$ e nas raízes $18 \%$ (AUGUSTINHO et al., 2008); nas folhas com 70\%, no caule $20 \%$ e nas raízes $10 \%$ (FRANCO, 2007).

\section{Conclusões}

O acúmulo de massa da matéria seca das mudas de caramboleira apresentou ajuste sigmoidal, enquanto o acúmulo dos nutrientes avaliados apresentou incremento quadrático, exceto $\mathrm{Mg}, \mathrm{P}$ e $\mathrm{Cu}$, que foi sigmoidal, obedecendo à seguinte sequência: $\mathrm{N}>\mathrm{K}>\mathrm{Ca}>\mathrm{P}>\mathrm{S}>\mathrm{Mg}>\mathrm{Fe}>\mathrm{Mn}>\mathrm{Zn}>\mathrm{B}>\mathrm{Cu}, \quad$ sendo maior nas folhas para todos os nutrientes, à exceção do $\mathrm{P}, \mathrm{Zn}, \mathrm{Fe}$ e $\mathrm{Cu}$.

O período de maior exigência de nutrientes foi entre 90 - 150 dias após o transplantio.

\section{Referências}

AUGUSTINHO, L. M. D.; PRADO, R. M.; ROZANE, D. E.; FREITAS, N. Acúmulo de massa seca e marcha de absorção de nutrientes em mudas de goiabeira 'Pedro Sato'. Bragantia, Campinas, v. 67, n. 3, p. 536-568, 2008.

BARBOSA, Z.; SOARES, I.; CRISÓTOMO, L. A. Crescimento de nutrientes por mudas de gravioleira. Revista Brasileira de Fruticultura, Jaboticabal, v. 25, n. 3, p. 519-522, 2003.

BASTOS, D. C. A cultura da carambola. Revista Brasileira de Fruticultura, Jaboticabal, v. 26, n. 2, p. 193-384, 2004.

BASTOS, D. C.; PIO, R.; SCARPARE FILHO, J. A.; LIBARDI, M. N.; ALMEIDA, L. F. P.; ENTELMANN, F. A. Diferentes substratos na produção de porta-enxertos de caramboleira. Ciência e Agrotecnologia, Lavras, v. 31, n. 2, p. 312-316, 2007.

BATAGLIA, O. C.; FURLANI, A. M. C.; TEIXEIRA, J. P. F.; FURLANI, P. R.; GALLO, J. R. Métodos de análise química de plantas. Campinas: Instituto Agronômico, 1983. (Boletim técnico, 78).

CHU, E. Y.; MÖLleR, M. R. F.; CARVALHO, J. G. Efeitos da inoculação micorrízica em mudas de gravioleira em solo fumigado e não fumigado. Pesquisa Agropecuária Brasileira, Brasília, v. 36, n. 4, p. 671-680, 2001.

CUNHA, R. J. P. Marcha de absorção de nutrientes em condições de campo e sintomatologia de deficiência de macronutrientes e do boro em mamoeiro (Carica papaya L.). 1979. Tese (Doutorado em Agronomia) - Escola Superior de Agricultura Luiz de Queiroz. Universidade de São Paulo, Piracicaba.

DONADIO, L. C.; SILVA, J. A. A.; ARAÚJO, P. S. R.; PRADO, R. M. Caramboleira (Averrhoa carambola L.). Jaboticabal: Sociedade Brasileira de Fruticultura, 2001. v. $1,81 \mathrm{p}$.

FAYAD, J. A.; FONTES, P. C. R.; CARDOSO, A. A.; FINGER, F. L.; FERREIRA, F. A. Absorção de nutrientes pelo tomateiro cultivado sob condições de campo e de ambiente protegido. Horticultura Brasileira, Brasília, v. 20, n. 1, p. 90-94, 2002.

FRANCO, C. F.; PRADO, R. M.; BRAGHIROLLI, L. F.; ROZANE, D. E. Marcha de absorção dos micronutrientes para mudas de goiabeiras cultivares Paluma e Século XXI. Bragantia, Campinas, v. 67, n. 1, p. 83-90, 2008.

. Curva de crescimento e marcha de absorção de macronutrientes em mudas de goiabeira. Revista Brasileira de Ciências do Solo, Viçosa, MG, v. 31, n. 6, p. 1.429-1.437, 2007.

FURLANI, P. R.; SILVEIRA, L. C. P.; BOLONHEZI, D.; FAQUIN, V. Cultivo hidropônico de plantas. Campinas: IAC, 1999. 52 p. (Boletim técnico, 180).

GRANGEIRO, L. C.; CECILIO FILHO, A. B. Acúmulo e exportação de macronutrientes pelo híbrido de melancia Tide. Horticultura Brasileira, Brasília, v. 22, n. 1, p. 9397, 2004.

HAAG, H. P.; OLIVEIRA, G. D.; BARBOSA, V.; SILVA NETO, J. M. de. Marcha de absorção dos nutrientes pelo tomateiro (Lycopersicum esculentum Mill) destinado ao processamento industrial. In: HAAG, H. O.; MINAMI, K. (Ed.). Nutrição mineral de hortaliças. Campinas: Cargill, 1981. p. 447-474.

HAYNES, R. J. Competitive aspects of the grass-legume association. Advances in Agronomy, New York, v. 33, n. 1, p. 227-261, 1980.

HOFFMAM, R. S. V. Análise de regressão. São Paulo: Ed. Huitec-Edusp, 1977, 339 p.

LOPES, P. S. N.; RAMOS, J. D.; RODRIGUES, M. G. V.; VICENTINI, S. Efeito de nitrocálcio e cloreto de potássio sobre o desenvolvimento de mudas de maracujáamarelo propagadas em tubetes. Revista Brasileira de Fruticultura, Cruz das Almas, v. 19, n. 3, p. 387-391, 1997.

MARSCHNER, H. Mineral nutrition of higher plants. New York: Academic Press, 1995. 889 p.

ROZANE, D. E.; PRADO, R. M.; FRANCO, C. F.; 
NATALE, W. Eficiência de absorção, transporte e utilização de macronutrientes por porta-enxertos de caramboleira, cultivados em soluções nutritivas. Ciência e Agrotecnologia, Lavras, v. 31, n. 4, p. 1020-1026, 2007.

SAS INSTITUTE. The SAS-system for windows: release 6.11 (software). Cary: Statistical Analysis System Institute, 1996.

SILVA JUNIOR, M.; MEDEIROS, J. F.; OLIVEIRA, F. H. T. de; DUTRA, I. Acúmulo de matéria seca e absorção de nutrientes pelo meloeiro "pele-de-sapo". Revista Brasileira de Engenharia Agrícola e Ambiental, Campinas Grande, v. 10, n. 2, p. 364-368, 2006.

SILVEIRA, R. L. V. A.; LUCA, E. F.; SILVEIRA, L. V. A.; LUZ, H. F. Matéria seca, concentração e acúmulo de nutrientes em mudas de Eucaliptus grandis em função da idade. Scientia Forestalis, Piracicaba, v. 2, n. 64, p. 136-149, 2003. 
